РАЗДЕЛ ІІІ. ТЕОРИЯ И МЕТОДИКА ПРОФЕССИОНАЛЬНОГО ОБРАЗОВАНИЯ. СПЕЦИАЛЬНОСТЬ 13.00 .08

\author{
ПРОФЕССИОНАЛЬНАЯ ДЕЯТЕЛЬНОСТЬ ПЕДАГОГА ДОШКОЛЬНОГО \\ ОБРАЗОВАНИЯ: ПРОБЛЕМЫ РАЗВИТИЯ МОТИВАЦИИ ИННОВАЦИОННОЙ \\ ДЕЯТЕЛЬНОСТИ И ПРОФЕССИОНАЛЬНО-ЛИЧНОСТНОГО ПОТЕНЦИАЛА
}

\title{
PROFESSIONAL ACTIVITY OF THE TEACHER OF PRESCHOOL EDUCATION: PROBLEMS OF DEVELOPMENT OF MOTIVATION FOR INNOVATION AND PROFESSIONAL AND PERSONAL POTENTIAL
}

\author{
БОРИСЕНКО Е.Н., \\ КОСТЮКОВА Н.С., \\ ШИНКАРЕВА Л.В.
}

Белгородский государственньй национальный исследовательский университет

\author{
BORISENKO E.N., \\ KOSTYUKOVA N.S., \\ SHINKAREVA L.V.
}

\author{
Belgorod National Research University
}

repinka05@mail.ru

doi: 10.18411/ppiip-03-2019-03

idsp: sciencepub-ppiip-03-2019-03

\section{АННОТАЦИЯ}

В статье освещаются различные аспекты профессиональной деятельности педагога дошкольного образования. В частности, затрагиваются проблемы развития мотивации к осуществлению инновационной деятельности педагога, как одного из видов профессиональной деятельности. Авторами рассматриваются проблемы развития профессионально-личностного потенциала педагога дошкольного образования.

КЛЮЧЕВЫЕ СЛОВА: профессиональная деятельность педагога дошкольного образования, мотивация инновационной деятельности, профессионально-личностный потенциал.

\section{ABSTRACT}

The article covers various aspects of the professional activities of the teacher of preschool education. In particular, the problems of the development of motivation for the implementation of innovative activities of the teacher, as one of the types of professional activity, are touched upon. The authors consider the problems of development of professional and personal potential of a teacher of preschool education.

KEYWORDS: professional activity of the teacher of preschool education, motivation to innovate, professional and personal potential

\section{ВВЕДЕНИЕ}

В настоящее время общество предъявляет высокие требования к профессиональной деятельности педагога дошкольного образования. Эффективность и уровень профессиональной деятельности обусловлены развитием мотивации инновационной деятельности специалиста и его профессионально-личностного потенциала. 


\section{ЦЕЛЬ ИССЛЕДОВАНИЯ}

На основании актуальности рассматриваемой нами темы целью нашего исследования стало выявление психолого-педагогических условий развития мотивации педагогов дошкольного образовательного учреждения к осуществлению инновационной деятельности и их профессионально-личностного потенциала.

\section{РЕЗУЛЬТАТЫ И ИХ ОБСУЖДЕНИЕ}

Нами были изучены и проанализированы научные работы в области педагогики и психологии профессионального развития педагога. Ученые А.А. Деркач, Э.Ф. Зеер, Е.А. Климова, Н.В. Кузьмина, Т.В. Кудрявцев, Л.М. Митина, К.К. Платонов, Н.С. Пряжников, А.А. Реан, Г.В. Суходольский, В.Д. Шадриков и др. отмечают формирующую роль профессионального и личностного потенциала специалиста.

В.П. Бабинцев и М.П. Куркина выявили, что понятие «потенциал» в исследованиях по философии, педагогике, психологии и социологии имеет различную трактовку. По мнению ученых, это позволяет применять понятие потенциала в различных интерпретациях в зависимости от специфики области научного знания. Они отмечают, что общим для всех определений в научных исследованиях остается «понимание «потенциала» как совокупности накопленных содержательных качеств объекта, которые могут быть целенаправленно реализованы в определенных условиях, а также усовершенствованны» (2).

В исследовании В.П. Бабинцева и М.П. Куркиной потенциал рассматривается как система свойств и качеств объекта, подлежащих и способных к развитию, к практическому воплощению в конкретных результатах развития (материально и нематериально проявленных), что позволяет судить о степени реализации потенциала в конкретных условиях (2).

Согласно основным положениям исследований В.П. Бабинцева и М.П. Куркиной мы сформулировали рабочее определение к понятию «профессионально-личностный потенциал педагога дошкольного образования», под которым мы понимаем систему свойств и качеств педагога дошкольного образования, подлежащих и способных к развитию, к практическому воплощению в конкретных результатах профессиональной деятельности (2).

H.M. Касьянова отмечает, что потенциал является многоуровневой и интегративной характеристикой личности субъекта профессиональной деятельности. По ее мнению, самый общий и фундаментальный уровень иерархии потенциалов человека это его биологический потенциал, вторым уровнем является психический потенциал индивида, третий уровень - личностный, четвертый уровень - профессиональноличностный потенциал, который наиболее полно проявляется и формируется в профессиональной сфере жизни человека, считает Н.М. Касьянова (4).

В нашем исследовании мы пришли к выводу, что профессионально-личностный потенциал педагога дошкольного образования представляет собой синтез взаимосвязанных структурных компонентов, к которым относятся: мотивационноценностный, когнитивно-волевой и операционально-действенный компоненты.

Показателями уровня развития профессионально-личностного потенциала педагога дошкольного образования являются эффективность решения профессиональнопедагогических задач развития и воспитания дошкольников, качество образовательного процесса в детском саду, уровень личностной комфортности педагога при ее осуществлении и степень его профессиональной активности.

Н.М. Касьянова считает, что развитие профессионально-личностного потенциала предполагает процесс становления и прогрессивного изменения личности под влиянием требований профессиональной деятельности и собственной активности, направленной на самосовершенствование и самоосуществление (1). 
Развитие профессионально-личностного потенциала педагога дошкольного образования - это непрерывный процесс, влияющий на профессионально-педагогическую деятельность в целом.

В качестве условий развития профессионально-личностного потенциала педагога дошкольного образования мы рассматриваем создание эффективной системы управления развитием профессионально-личностного потенциала педагога и построение постоянно действующей системы непрерывного образования педагогических кадров в условиях дошкольного образовательного учреждения.

Одним из показателей уровня развития профессиональной деятельности педагога дошкольного образования является ее инновационная направленность. В связи с этим инновационная деятельность может рассматриваться как вид профессиональной деятельности педагога. При этом мотивационная составляющая инновационной деятельности обусловливает целесообразный и сознательный характер действий педагога дошкольного образования и определяет его профессионально-личностные возможности. В научных исследованиях мотивационный компонент выделяется наряду с креативным, технологическим и рефлексивным компонентами инновационной деятельности педагогов образовательных учреждений (Ю.Н. Кулюткин, В.П. Ларина, А.В. Лоренсов, И.Е. Пискарева, М.М. Поташник, В.А. Сластенин, Н.П. Фетискин, Л.М. Фридман, А.И. Щербаков и др.),

А.С.Ильин отмечает, что «инновационная деятельность в образовании характеризуется разработкой и внедрением принципиально новых образов содержания и технологий обучения, наличием носителей, которые данную деятельность осуществляют, а инновационная личность характеризуется таким качеством как способность к преобразованию действительности на основе ответственности и творчества» (3).

Инновационная деятельность педагога дошкольного образовательного учреждения является спецефической по своим целям и задачам, содержанию, внешним и внутренним условиям, средствам, проявлениям мотивации педагога. Позитивное или негативное отношение к инновационной деятельности в целом определяется иерархией мотивов педагога дошкольного образования, поэтому актуальным является понимание того, что инновационная деятельность невозможна без четко выстроенной мотивации педагогического труда.

Мотивация педагога дошкольного образования к осуществлению инновационной деятельности включает систему мотивов, побуждающей специалиста действовать специфическим, целенаправленным образом в отношении инноваций в образовательном процессе детского сада. Мотивация педагога к осуществлению инновационной деятельности выражается в его потребности и стремлении к профессиональному саморазвитию в области инновационной деятельности, личностному росту через повышение образовательного уровня в вопросах инноватики. А.А. Атласова и Ф.Д. Товарищева считают, что мотивация к инновационной деятельности может выражаться в отношении педагогов к проблеме необходимости внедрения инновационных технологий в образовательный процесс, устойчивым интересом к теоретическим проблемам, научным исследованиям и практической деятельности в области инноваций (1).

Э.Г. Скибицкий, И.Э. Толстова и инновационная деятельность строится под влиянием доминирующих мотивов. К этим мотивам они относят:

1) внешние стимулы (материальное вознаграждение, присвоение более высокого разряда, по служебной необходимости и др.);

2) мотивы внешнего самоутверждения педагога или мотивы престижа и др.;

3) профессиональный мотив (желание учить и воспитывать, направленность инновации на обучающихся и др.); 
4) мотивы личностной самореализации (5).

На основании изучения психолого-педагогической литературы мы пришли к тому, что процесс развития мотивации педагогов дошкольного образовательного учреждения к осуществлению инновационной деятельности будет эффективным, если учитывать следующие психолого-педагогические условия: создание инновационной среды в дошкольном образовательном учреждении; формирование инновационного поведения у педагогов дошкольного образовательного учреждения; содействие педагогам дошкольного образовательного учреждения в карьерном росте.

Важным условие для развития мотивации педагогов дошкольного образовательного учреждения к осуществлению инновационной деятельности является содействие педагогам в карьерном росте.

\section{ЗАКЛЮЧЕНИЯ}

Таким образом, качество и уровень профессиональной деятельности педагога дошкольного образования обусловлена развитием мотивации к осуществлению инновационной деятельности и профессионально-личностного потенциала специалиста, что, в свою очередь, обеспечивает высокий уровень решения профессиональнопедагогических задач развития и воспитания подрастающего поколения. Эти аспекты важно учитывать в процессе организации методической работы старшего воспитателя дошкольного образовательного учреждения.

$$
* * *
$$

1. Атласова А.А., Товарищева Ф.Д. Инновационная педагогическая деятельность как феномен современного образования // Научно-методический электронный журнал «Концепт». 2016. Т. 30. С. 119-124. URL: http://e-koncept.ru/2016/56599.htm.

2. Бабинцев В.П., Куркина М.П. Человеческий потенциал как научная категория // Научные ведомости. Серия Философия. Социология. Право. 2012. № 8 (127). Выпуск 20. С. 223-229.

3. Ильин А.С. Мотивация педагога к инновационной деятельности: эрзац или реальность // Научное обеспечение системы повышения квалификации кадров. Выпуск 2(11). 2012. С. 69-74.

4. Касьянова Н.М. Технологический аспект формирования профессионально-личностного потенциала руководителя // URL: https://core.ac.uk/download/pdf/141677211.pdf

5. Скибицкий Э.Г., Толстова И.Э., Шеффель И.Э. Методика профессионального обучения. Новосибирск. 2008. $166 \mathrm{c}$. 